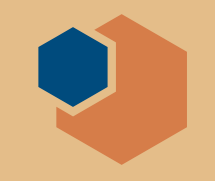

\title{
Brexit leaves UK scientific research community in uncertainty
}

$\mathrm{T}_{\mathrm{r}}^{\mathrm{h}}$ he United Kingdom's scientific research community reacted with concern when Britain voted to leave the EU on June 23 of this year. Many in the community had campaigned against "Brexit," as the leave campaign became known, on the grounds that the UK is a major beneficiary of the EU's support for research. One pre-ballot poll found that $93 \%$ of research scientists and engineers thought that the EU was a "major benefit" to UK research.

The science community's fears seemed to have foundation. Within days of the referendum, researchers were reporting a backlash among their European counterparts. European researchers working in the UK also began to worry about their future, and the risk that they would have to leave when Brexit finally happens.

One sign of the feeling within the UK's research community came when Britain's newest Nobel laureate, Sir J. Fraser Stoddart, joint recipient of this year's chemistry Prize for his work on the design and synthesis of machines on a molecular scale, found himself in demand by the media. He used his sudden fame to protest the likely impact of Brexit on the UK's science community. He told the BBC that international collaboration had been "absolutely critical" to his own successes. "Today I am distressed that

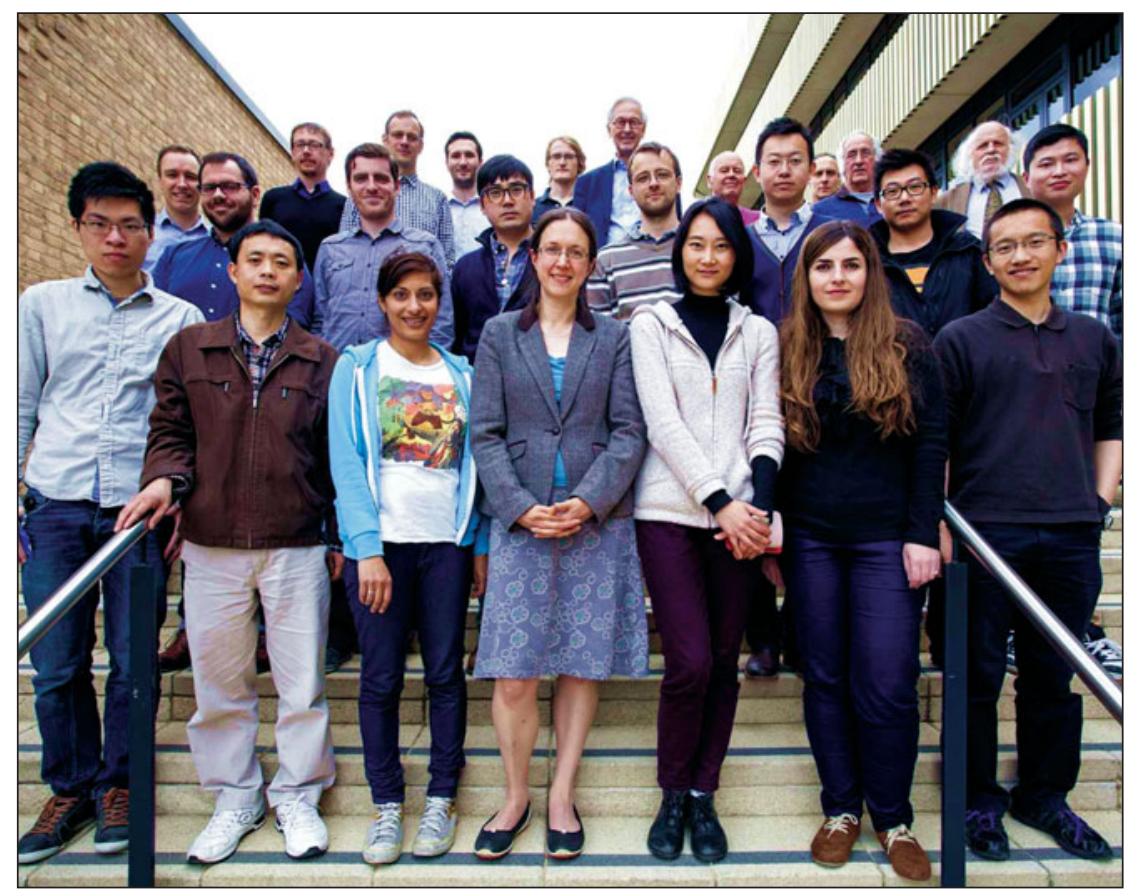

If the UK leaves the EU it could affect the freedom of researchers to move between the UK and EU countries. Currently, researchers of Sir Colin Humphreys's gallium nitride group at the University of Cambridge come from Germany, Ireland, The Netherlands, and France as well as China and Iran. $\mathrm{He}$ credits his ongoing international team for research that is "being exploited by the UK industry Plessey, which is manufacturing LEDs using our technology at its factory in Plymouth, UK." the UK is looking at a situation where it would cut off that supply. This is not good news.... I would hope that this whole business of Brexit would just go away or had not happened."

The UK may contribute more to the EU's budget than it gets back, a major issue in the referendum campaign, but this is not true for research. Before the referendum, The Royal Society, the UK's leading learned society, pointed out that between 2007 and 2013 the UK contributed $€ 5.4$ billion to EU research and development. "During this time, the UK received $€ 8.8$ billion in direct EU funding for research, development and innovation activities."

Financial support for research comes mostly through a series of five-year Framework Programmes. (The exact duration depends on how long the EU's 28 member governments take to agree on what they want to do.) In the Seventh Framework Programme (FP7), from 2007 to 2013 , the UK received around $€ 7$ billion. The EU is now awarding grants for the next Framework Programme, known as Horizon 2020, with a budget of $€ 74.8$ billion for the period 2014-2020.

The UK's success rate in bidding for funds in FP7 was $22.8 \%$ against an EU average of $20.5 \%$. According to The Royal Society, $71 \%$ of the funds awarded to the UK during FP7 went to universities. A survey by the Campaign for Science and Engineering (CaSE) and the Engineering Professors' Council (EPC) found that EU government sources made up $10 \%$ of income in higher education institutions in 2013 to 2014.

The UK also ranked second, after Germany, among the 28 member states in the number of participants and cash received. According to The Royal Society, "EU research funding through Framework Programme 7 represented 
$3 \%$ of UK expenditure on research and development between 2007 and 2013." When the House of Lords Science and Technology Select Committee carried out its inquiry "EU membership and UK science," it said, "We heard from universities that this funding is equivalent to having another Research Council."

The other major issue in Brexit is the movement of students and researchers throughout Europe. The "free movement" of citizens is a cornerstone of the EU's foundations. The threat of "cheap labor" from Eastern Europe, including such countries as Romania, Hungary, and Poland, fueled much of the anti-EU sentiment that led to the Brexit vote. The grassroots lobby group, Scientists for EU, claims that "in the 'science and maths' higher education workforce in the UK, $21 \%$ are immigrants from the EU."

The EU has specific mechanisms to promote the movement of researchers throughout Europe. For example, Marie Curie awards allow researchers to work in different countries, sectors, or disciplines. The CaSE EPC report found that "EU funding appears to be particularly important as $18 \%$ of full-time equivalent engineering academic staff on fixed-term contracts were funded by EU government sources and 4\% by other EU sources."

Even before the referendum, there was growing concern that the UK would be less attractive for students. In a response to the Brexit vote, Baroness Julia King, Vice-Chancellor and Chief Executive of Aston University, told MRS Bulletin, "The perception that the UK is not going to be welcoming to foreigners has already affected overseas student numbers."

There were also concerns about the impact of Brexit on research. Sir Colin Humphreys, Director of Research in the Department of Materials Science and Metallurgy at the University of Cambridge, said that "Brexit is bad news for my group. Our interaction with both industries and universities in other European countries is so strong, we receive so many talented European scientists to spend time in our group."

Humphreys, the guiding light behind the world leading Cambridge Centre for Gallium Nitride, told MRS Bulletin,
"I have had many EU grants, ranging from Marie Curie Network grants to major multi-million Euro grants. The support I have had from the EU has been extremely valuable." Humphreys added, "It has led to research breakthroughs and it has also enabled industries to have new and improved products. It has helped Plessey to be the first manufacturer in the world to have GaN on silicon LEDs [light-emitting diodes] commercially available."

Neil Alford, Chair in Materials and Vice Dean for Research in the Faculty of Engineering at Imperial College London, says that his group, which researches functional materials, "began life with tons of EU funding. It really got us started." The Materials Department has many Marie Curie Research Fellows, he adds.

In August, the government tried to calm the nerves of the research community. Jo Johnson MP, Minister of State for Universities, Science, Research and Innovation, said that it was "business as usual for Horizon 2020 projects.” He also tried to dispel fears about any sudden loss of EU funding. "For research activity [to be] bid for competitively while we remain a member of the EU, we will work with the Commission to ensure payment when funds are awarded," he says. This intervention coincided with a statement from the Treasury that it will "underwrite the payment of such awards, even when specific projects continue beyond the UK's departure from the EU."

Despite these assurances, there are signs that Brexit is already affecting the behavior of researchers. As Humphreys put it: "It is too early to say if there are any obvious effects yet, although I instinctively feel that other European partners are much less likely to contact the UK to be a partner in grant proposals which are being written now." He also confided that "I am no longer giving priority to writing grant proposals with Europe." He fears that such proposals are much less likely to be successful than in the past.

Alford makes a similar point. As yet, he says, there has been little immediate impact, "but a lot of very, very upset folk. A real kick in the teeth. The main effect [of Brexit] will be a possible barrier to UK cooperation with the EU."
The timetable for Brexit remains unclear. The government has said that it will begin the process in March 2017. In theory this fires the starting pistol on a two-year process, but few expect the UK to have completed negotiations within that period, with trade and migration at the top of the agenda.

As yet the research community has little idea of where it will stand when the UK finally leaves the EU. The only clue so far is a Treasury statement that "we expect to ensure that close collaboration between the UK and the EU in science continues."

The UK government will come under pressure to break its silence on its postBrexit plans for research. The House of Lords Science and Technology Select Committee is conducting a follow-up inquiry to its earlier pre-ballot report "EU membership and UK science." An early witness pointed out that Brexit coincided with a major change in the organization of science management in the UK. The government is merging the existing Research Councils and Innovate UK, previously the Technology Strategy Board (see the August 2016 issue of MRS Bulletin, p. 584), into a single body, UK Research and Innovation (UKRI).

John Womersley, Chief Executive, Science and Technology Facilities Council and Chair of the European Strategy Forum on Research Infrastructures, expressed the view that many in the scientific community hope that "UKRI will be strong advocates for science and research, in particular what science and research needs the Government to negotiate on in the context of Brexit."

At press time, MRS Bulletin received notice that the House of Lords Science and Technology Select Committee published a letter from Jo Johnson and Robin Walker, MP, Parliamentary Under Secretary of State for Exiting the EU, stating that "Jo Johnson will be writing to a number of senior representatives of UK research and innovation to invite them to join a consultative forum to discuss opportunities and issues arising from the UK's exit from the European Union."

It looks like the UK's research sector is in for interesting times.

Michael Kenward 


\section{MRS ENERGY @}

\section{SUSTAINABILITY}

\section{A Review Journal}



MRS Energy \& Sustainability-A Review Journal publishes reviews on key topics in materials research and development as they relate to energy and sustainability. Review topics include new R\&D of both established and new areas; systems integration; and objective application of economic, sociological and governmental models, enabling research and technological developments. The reviews are set in an integrated context of scientific, technological and sociological complexities relating to environment and sustainability.

\footnotetext{
는 David S. Ginley

퐁 National Renewable Energy Laboratory, USA

z David Cahen

के Weizmann Institute of Science, Israel

을 Elizabeth A. Kócs

프 University of Illinois at Chicago, USA
} 